\title{
Diagnostic and Prognostic Significance of Lung Function Tests in Chronic Obstructive Pulmonary Disease \& Cardiovascular Diseases
}

\author{
Usha Rani Moravineni ${ }^{1}$, Srinivasa Rao Malladi², Sudhakar P. V. ${ }^{3}$, Bhagya Lakshmi Atla ${ }^{4}$, Vijay Kumar K.V.V \\ Satyanarayana Raju P. ${ }^{6}$, Sandhya M.7, Susmitha Madhuri T. ${ }^{8}$ \\ 1, 6, 7,8 Department of Physiology, Andhra Medical College, Visakhapatnam, Andhra Pradesh, India. \\ ${ }^{2}$ Department of Cardiology, Andhra Medical College, Visakhapatnam, Andhra Pradesh, India. \\ ${ }^{3}$ Department of Plastic Surgery, Andhra Medical College, Visakhapatnam, Andhra Pradesh, India. \\ ${ }^{4}$ Department of Pathology, Andhra Medical College, Visakhapatnam, Andhra Pradesh, India. \\ ${ }^{5}$ Department of Pulmonology, Andhra Medical College, Visakhapatnam, Andhra Pradesh, India.
}

\section{ABSTRACT}

\section{BACKGROUND}

We wanted to assess the significance of diagnosis and prognosis of lung function tests in chronic obstructive pulmonary diseases (COPD) \& cardiovascular diseases in this study.

\section{METHODS}

This study was conducted among 200 patients in the outpatient departments of General Medicine and Cardiology of King George Hospital/AMC. Data was collected with Spirometer machine (Digital), HELIOS-401, Recorders \& Medicare Systems Pvt. Ltd, Haryana, Chandigarh-160002, India. The data were entered into MS Excel and analysed in SPSS v21.

\section{RESULTS}

Of the 200 patients enrolled in the study, 146 (73\%) were males and 54 (27\%) were females with an average age of $50.38 \pm 9.86$ yrs. In the study population, pulmonary function parameters were significantly different in COPD compared to control and a P-value of less than 0.05 was considered statistically significant. The difference in pulmonary function parameters between Controls, COPD, Post MI \& Post MI \& COPD groups was statistically significant. Whereas the pulmonary function parameters between the post-MI and controls were not statistically significantly different with a P-value of more than 0.05 . In the study population, the pulmonary function parameters were significantly different between the Post MI and control, COPD and control, Post MI with COPD and control.

\section{CONCLUSIONS}

The diagnosis of COPD was done by the Lung function test which is considered the gold standard test. The lung function was improved in Post MI cases of more than one-month duration.

\section{KEY WORDS}

Lung Function Tests, COPD, Cardiovascular Diseases, Spirometry
Corresponding Author: Dr. Usha Rani Moravineni, Professor and HOD, Department of Physiology, Andhra Medical College, Visakhapatnam, Andhra Pradesh, India. E-mail: ushaprasad6@gmail.com

DOI: $10.14260 /$ jemds/2022/40

How to Cite This Article: Moravineni UR, Malladi SR, Sudhakar PV, et al. Diagnostic and prognostic significance of lung function tests in chronic obstructive pulmonary disease \& cardiovascular diseases. J Evolution Med Dent Sci 2022;11(01):208-212, DOI: $10.14260 / \mathrm{jemds} / 2022 / 40$

Submission 01-01-2022,

Peer Review 15-01-2022,

Acceptance 17-01-2022,

Published 29-01-2022.

Copyright (C) 2022 Usha Rani Moravineni et al. This is an open access article distributed under Creative Commons Attribution License [Attribution 4.0 International (CC $B Y 4.0)]$ 


\section{BACKGROUND}

Pulmonary function tests are non-invasive tests that measure lung function in terms of lung volume, capacity, rate of flow, and gas exchange. Pulmonary function tests can be done in 2 methods - Spirometry and Plethysmography of which spirometry is the most commonly used method. The diagnosis of respiratory disorders is yielded doubly in primary care by the use of spirometry which is safe and accurate for early diagnosis and also simple and inexpensive. There is significant morbidity and mortality throughout the world in relation to ischemic heart diseases (IHD) and chronic obstructive pulmonary diseases (COPD).

Since clinical symptoms like dyspnoea and cough frequently overlap, the combination of these two conditions poses many difficulties in the diagnosis. There is sparse data addressing the combination of both diseases even though they have been extensively studied separately. COPD patients with IHD have a poor prognosis compared to those with either disease alone and hence it is important to identify and appropriately manage chronic obstructive airway disease in such patients. COPD is often undetected in cardiac patients as only one-third of them undergo spirometry, which is the gold standard for diagnosis of it, at least once with the remaining being underutilised.

"One-third of people die of cardiovascular disease as it is a common comorbidity and cause of death in people with chronic obstructive pulmonary disease (COPD)". ${ }^{1}$ To lessen the burden of COPD it is very important to reduce cardiovascular disease in this population.

"People with COPD have a higher risk of myocardial infarction (MI) than people without COPD according to various studies". ${ }^{2-4}$ "Smoking is a major risk factor for the increased risk of MI in patients with COPD apart from several other cardiovascular risk factors including hypertension, inactivity, diabetes, old age and poor diet that are also prevalent in patients having COPD".5-7 "There is an association found between reduced $\mathrm{FEV}_{1}$ (forced expiratory volume $1 \mathrm{~s}$ ) and cardiovascular mortality in the general population according to several studies". ${ }^{8}$ There is an increased risk of MI possibly being mediated through increased systemic inflammation or reduced $\mathrm{FEV}_{1}$ in people with COPD which is thought to be an independent risk factor for MI.9 "Although the finding that patients with COPD have greater in-hospital and short-term mortality has not been found by all investigators, mortality is worse in patients with COPD in hospital and following discharge after an MI than in those without COPD according to some of them". ${ }^{10-15}$

\section{Objectives}

1. To evaluate the lung function status by pulmonary function tests in patients having COPD.

2. To evaluate the lung function status by pulmonary function tests in patients of more than 1 month of Post MI.

3. To determine the diagnostic \& prognostic significance of lung function tests in COPD and cardiovascular diseases.

\section{METHODS}

Written informed consent was taken from each individual in the local language for the study after permission from the Institutional Ethics Committee of Andhra Medical College / King George Hospital, Visakhapatnam. A sample size of 200 that included both chronic obstructive pulmonary diseases \& cardiovascular disease cases was in the present comparative cross-sectional study. The sample was collected from patients attending the outpatient departments of General Medicine and Cardiology of King George Hospital/AMC. Data was collected with Spirometer machine (Digital), HELIOS-401, Recorders \& Medicare Systems Pvt. Ltd, Haryana, Chandigarh-160002, India.

\begin{tabular}{|ccccc|}
\hline $\begin{array}{c}\text { Control } \\
\text { Cases }\end{array}$ & $\begin{array}{c}\text { COPD } \\
\text { Cases }\end{array}$ & $\begin{array}{c}\text { Post MI Cass - 1 } \\
\text { Month }\end{array}$ & $\begin{array}{c}\text { COPD + 1 Month } \\
\text { Post MI Cases }\end{array}$ & $\begin{array}{c}\text { Total } \\
\text { Cases }\end{array}$ \\
50 & 50 & 50 & 50 & 200 \\
\hline \multicolumn{2}{|c|}{ The Types of Samples Collected Were Shown in the Following Table } \\
\hline
\end{tabular}

\section{Statistical Analysis}

SPSS v21 was used for the analysis and its data were entered into MS Excel. Age and gender were represented in percentages. Unpaired student t-test was used to compare the pulmonary function parameters among the control and other groups. Analysis of variance (ANOVA) was used to evaluate the differences among the groups and a P-value of 0.05 was considered statistically significant.

\section{Inclusion Criteria}

1. Subjects who gave consent to the study

2. Both genders

3. Age between 30 and 60 years

4. Patients with myocardial infarction of more than 1 month of duration.

5. Patients with a history of chronic obstructive pulmonary disease

6. Patients suspected to be COVID, on test negative (RTPCR) were enrolled.

\section{Exclusion Criteria}

1. Patients who were not willing to participate.

2. Patients with a history of recent surgery of the head, chest, stomach, and eyes.

3. Patients with uncontrolled hypertension, unstable angina, or a recent myocardial infarction or stroke $[<1$ month).

4. Patients with a history of the acute phase of communicable diseases.

5. Active haemoptysis, active tuberculosis and a history of syncope associated with forced exhalation.

6. Individuals with a history of pneumothorax.

7. Individuals with arrhythmias.

8. Patients with suspect COVID positive. 


\section{RESULTS}

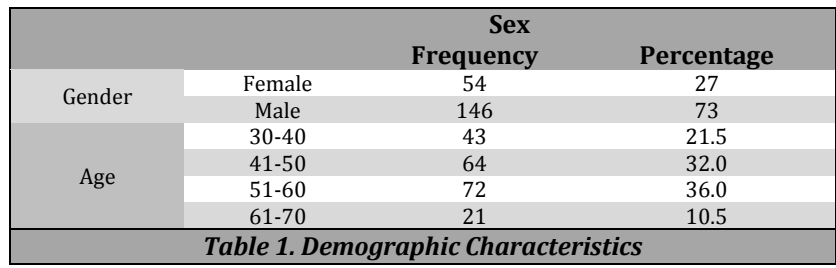

\begin{tabular}{|c|c|c|c|}
\hline \begin{tabular}{|c|} 
Lung \\
Volumes/Parameters
\end{tabular} & Group & Mean \pm SD & P-Value \\
\hline \multirow[t]{2}{*}{ FVC } & Post MI & $2.44 \pm 0.49$ & \multirow{2}{*}{0.388} \\
\hline & Control & & \\
\hline \multirow[t]{2}{*}{ FEV 1} & Post MI & $2.25 \pm 0.42$ & \multirow{2}{*}{0.678} \\
\hline & Control & $2.30 \pm 0.67$ & \\
\hline \multirow{2}{*}{ FEV1/FVC } & Post MI & $92.52 \pm 5.55$ & \multirow[t]{2}{*}{0.379} \\
\hline & Control & $91.17 \pm 9.31$ & \\
\hline \multirow{2}{*}{ FEF 25-75 } & Post MI & $3.07 \pm .76$ & \multirow{2}{*}{0.430} \\
\hline & Control & $3.22 \pm 1.06$ & \\
\hline \multirow{2}{*}{ PEFR } & Post MI & $4.92 \pm 1.44$ & \multirow{2}{*}{0.237} \\
\hline & Control & $5.32 \pm 1.82$ & \\
\hline \multirow{2}{*}{ FIVC } & Post MI & $2.49 \pm 1.03$ & \multirow{2}{*}{0.150} \\
\hline & Control & $2.67 \pm 1.27$ & \\
\hline \multirow{2}{*}{ SVC } & Post MI & $2.36 \pm 0.54$ & \multirow{2}{*}{0.165} \\
\hline & Control & $2.53 \pm 0.70$ & \\
\hline \multirow{2}{*}{ ERV } & Post MI & $0.53 \pm 0.66$ & \multirow{2}{*}{0.321} \\
\hline & Control & $0.68 \pm 0.90$ & \\
\hline \multirow{2}{*}{ IRV } & Post MI & $0.96 \pm 0.75$ & \multirow{2}{*}{0.218} \\
\hline & Control & $1.18 \pm 1.01$ & \\
\hline \multirow{2}{*}{ MV } & Post MI & $23.20 \pm 8.98$ & \multirow{2}{*}{0.145} \\
\hline & Control & $26.36 \pm 12.30$ & \\
\hline \multirow{2}{*}{ MVV } & Post MI & $41.84 \pm 13.52$ & \multirow{2}{*}{0.510} \\
\hline & Control & $43.82 \pm 16.27$ & \\
\hline \multirow{2}{*}{ MRF } & Post MI & $30.21 \pm 8.61$ & \multirow{2}{*}{0.886} \\
\hline & Control & $29.97 \pm 8.10$ & \\
\hline \multirow{2}{*}{ IT } & Post MI & $6.93 \pm 0.80$ & \multirow{2}{*}{0.427} \\
\hline & Control & $7.07 \pm 0.94$ & \\
\hline \multirow{2}{*}{ ET } & Post MI & $6.70 \pm 0.83$ & \multirow{2}{*}{0.623} \\
\hline & Control & $6.62 \pm 0.82$ & \\
\hline
\end{tabular}

The functional parameters between the post-MI and control like FVC, FEV1, PEFR, FIVC and ET were not statistically significantly different with a P-value of more than 0.05 in the study population.

\begin{tabular}{|c|c|c|c|}
\hline SBP & Group & Mean \pm SD & P-Value \\
\hline \multirow{2}{*}{ FVC } & COPD & $1.33 \pm 0.57$ & \multirow{2}{*}{0.000} \\
\hline & Control & $2.56 \pm 0.86$ & \\
\hline \multirow{2}{*}{ FEV 1} & COPD & $1.01 \pm 0.56$ & \multirow[t]{2}{*}{0.000} \\
\hline & Control & $2.30 \pm 0.67$ & \\
\hline \multirow{2}{*}{ FEV1/FVC } & COPD & $78.55 \pm 24.31$ & \multirow[t]{2}{*}{0.001} \\
\hline & Control & $91.17 \pm 9.31$ & \\
\hline \multirow{2}{*}{ FEF 25-75 } & COPD & $1.46 \pm 1.17$ & \multirow[t]{2}{*}{0.000} \\
\hline & Control & $3.22 \pm 1.06$ & \\
\hline \multirow{2}{*}{ PEFR } & COPD & $2.45 \pm 1.63$ & \multirow{2}{*}{0.000} \\
\hline & Control & $5.32 \pm 1.82$ & \\
\hline \multirow{2}{*}{ FIVC } & COPD & $1.59 \pm 0.90$ & \multirow[t]{2}{*}{0.000} \\
\hline & Control & $2.67 \pm 1.27$ & \\
\hline \multirow{2}{*}{ SVC } & COPD & $1.75 \pm 0.53$ & \multirow{2}{*}{0.000} \\
\hline & Control & $2.53 \pm 0.70$ & \\
\hline \multirow{2}{*}{ ERV } & COPD & $0.48 \pm 0.61$ & \multirow[t]{2}{*}{0.182} \\
\hline & Control & $0.68 \pm 0.90$ & \\
\hline \multirow{2}{*}{ IRV } & COPD & $0.68 \pm 0.68$ & \multirow{2}{*}{0.004} \\
\hline & Control & $1.18 \pm 1.01$ & \\
\hline \multirow{2}{*}{ MV } & COPD & $17.50 \pm 9.61$ & \multirow[t]{2}{*}{0.000} \\
\hline & Control & $26.36 \pm 12.30$ & \\
\hline \multirow[b]{2}{*}{ MVV } & COPD & $27.22 \pm 15.61$ & \multirow[t]{2}{*}{0.000} \\
\hline & Control & $43.82 \pm 16.27$ & \\
\hline \multirow{2}{*}{ MRF } & COPD & $28.26 \pm 8.20$ & \multirow[t]{2}{*}{0.296} \\
\hline & Control & $29.97 \pm 8.10$ & \\
\hline \multirow[b]{2}{*}{ IT } & COPD & $5.73 \pm 1.21$ & \multirow[t]{2}{*}{0.000} \\
\hline & Control & $7.07 \pm 0.94$ & \\
\hline \multirow{2}{*}{ ET } & COPD & $6.92 \pm 1.14$ & \multirow{2}{*}{0.135} \\
\hline & Control & $6.62 \pm 0.83$ & \\
\hline$T c$ & parison & COPD and & \\
\hline
\end{tabular}

Pulmonary function parameters were significantly different in COPD compared to control like FEF25-75, PEFR, SVC, FIVC, FVC, FEV1, FEV1/FVC, IRV, MV, MVV and IT were statistically significant with a P-value of less than 0.05

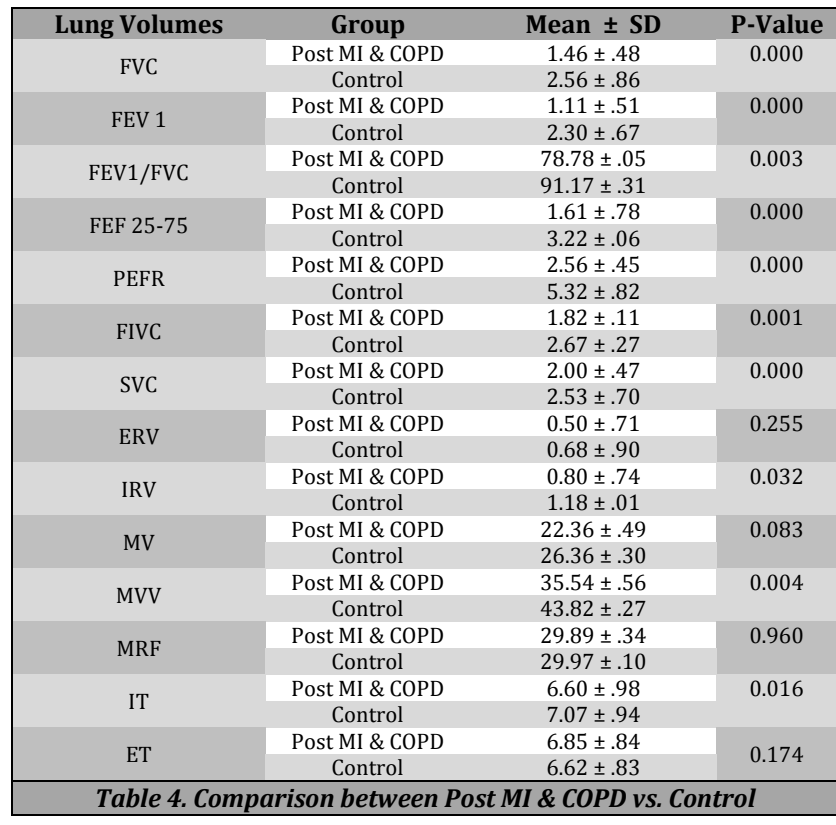

Pulmonary function parameters were significantly different in Post MI \& COPD compared to control like FIVC, FEF25-75, PEFR, FEV1, FEV1/FVC, SVC, IRV, MVV, MRF and IT were statistically significant with a P-value less than 0.05

\section{DISCUSSION}

Of the total 200 patients enrolled for the study, 146 (73\%) were males and $54(27 \%)$ were females with an average age of $50.38 \pm 9.86$ yrs. (Table 1 )

In the absence of any primitive lung disease, restrictive and /or obstructive lung impairment can be detected close to acute MI. The evaluation of lung function should be delayed until after one month of recovery in order to avoid diagnostic pitfalls. An increase in the pulmonary water, which may be very minimal with uncomplicated myocardial infarction and that, stays basically in the pulmonary interstitial space but becomes more severe progressively leading to alveolar flooding and marked impairment of pulmonary function is the basic pathophysiologic mechanism responsible for abnormalities of pulmonary function. With therapy, the above condition will be improved and there will be a gradual improvement in pulmonary function. ${ }^{16,17,18}$ In the present study, in post-MI more than one month, all the lung parameters were not statistically significant with a P-value of more than 0.05 (Table 2) which indicated the improvement of lung function which is one of the important factors for good prognosis with which, the therapy can also be modified.

In the previous similarly related studies done by 1 . C A Hales, H Kazemi et al. and J Ibáñez Juvé, 2. M Fiol Sala, J M Raurich Puigdevall, J M Abadal Centellas, S García Moris et al. and 3. Mauro Contini, Edoardo Conte, Piergiuseppe Agostoni, the above statement was mentioned.

Spirometry is the standard respiratory function test used for the diagnosis of chronic obstructive pulmonary disease (COPD. "The criterion for diagnosis defined in guidelines is based on the FEV1/FVC ratio forced expiratory ratio (FER) and its severity is based on forced expiratory volume in one second (FEV1) from measurements obtained during maximal 
forced expiratory manoeuvres." 19,20 So, pulmonary function parameters like FVC, FEV1, FEV1/FVC, FEF25-75, PEFR, FIVC, SVC, IRV, MV, MVV and IT measured with spirometry in this study were statistically significant (with a P-value less than 0.05 ) compared to the control group(Table 3). The cause for lesser values of lung parameters was airway obstruction. So, the previous two studies published in November 2014 Journal of Thoracic Disease 6 (11):1557-1569 DOI:10.3978/j.issn.2072-1439.2014.08.18 (Source PubMed) is also telling the same statement.

"Chronic respiratory diseases, such as chronic obstructive pulmonary disease (COPD) including emphysema, are among the leading causes of morbidity and mortality, claiming some 2.5 million lives worldwide in 2015. Moreover, chronic respiratory diseases increase cardiac overload and may result in cardiac impairment, thus increasing morbidity and further affecting the quality of life". 21

"Recent studies reported on the association of impaired cardiac function and maladaptive deformation with respiratory parameters. Watz et al. showed decreased cardiac chamber sizes and impaired left ventricular diastolic filling patterns as well as global right-heart dysfunction in patients with known hyperinflation". 22

There is a greater risk of heart attack and stroke in people having a reduced lung capacity because they show evidence of inflammation.

Older adults with COPD have an increased risk of cardiovascular disease because inflammation is a risk factor for the hardening of the arteries or atherosclerosis.

"Establishing whether systemic inflammation leads to reduced lung function or whether lower lung function leads to inflammation is difficult, but this research suggests that the association between poor lung function and cardiovascular disease may be mediated by an inflammatory mechanism." $23,24,25$

In the previous study, BMJ Specialty Journals. "Reduced Lung Capacity Linked To Cardiovascular Disease By Inflammation." Science Daily, 5 July 2007. www.sciencedaily.com/releases/2007/07/070702145409. htm is showing the same results as the present study (Table 4).

\section{CONCLUSIONS}

- The diagnosis of COPD is done by the Lung function test which is considered as the gold standard test for the diagnosis of the same.

- $\quad$ Lung function was improved in post-MI cases of more than one-month duration.

- Lung function was not improved if MI was associated with COPD.

- To know the status of the lung function in cases of MI associated with COPD, further studies may be needed with larger sample size.

Data sharing statement provided by the authors is available with the full text of this article at jemds.com.

Financial or other competing interests: None.

Disclosure forms provided by the authors are available with the full text of this article at jemds.com.
We thank the multidisciplinary research unit (MRU) Government of India, Ministry of Health \& family welfare, Department of Health Research, New Delhi, for the infrastructure \& faculty provided to conduct the study. We also thank Dr P. V. Sudhakar sir for providing guidance and feedback throughout this project. We would also like to thank Dr. Bhagya Lakshmi for her consistent support and guidance during the course of this project. We also thank our postgraduates Dr Sandhya and Dr Madhuri for their continuous help in collecting the data for this project.

\section{REFERENCES}

[1] Sin D, Anthonisen N, Soriano J, et al. Mortality in COPD: role of comorbidities. Eur Respir J 2006;28(6):1245-57.

[2] Curkendall SM, deLuise C, Jones JK, et al. Cardiovascular disease in patients with chronic obstructive pulmonary disease, Saskatchewan Canada Cardiovascular disease in COPD patients. Ann Epidemiol 2006;16(1):63-70.

[3] Feary JR, Rodrigues LC, Smith CJ, et al. Prevalence of major comorbidities in subjects with COPD and incidence of myocardial infarction and stroke: a comprehensive analysis using data from primary care. Thorax 2010;65(11):956-62.

[4] Schneider C, Bothner U, Jick SS, et al. Chronic obstructive pulmonary disease and the risk of cardiovascular diseases. Eur J Epidemiol 2010;25(4):253-60.

[5] Divo M, Cote C, de Torres JP, et al. Comorbidities and risk of mortality in patients with chronic obstructive pulmonary disease. Am J Respir Crit Care Med 2012;186(2):155-61.

[6] Mannino D, Thorn D, Swensen A, et al. Prevalence and outcomes of diabetes, hypertension and cardiovascular disease in COPD. Eur Respir J 2008;32(4):962-9.

[7] Pitta F, Troosters T, Spruit MA, et al. Characteristics of physical activities in daily life in chronic obstructive pulmonary disease. Am J Respir Crit Care Med 2005;171(9):972-7.

[8] Sin DD, Wu LL, Man SFP. The relationship between reduced lung function and cardiovascular mortality. Chest 2005;127(6):1952-9.

[9] Donaldson GC, Hurst JR, Smith CJ, et al. Increased risk of myocardial infarction and stroke following exacerbation of COPD. Chest 2010;137(5):1091-7.

[10] Andell P, Koul S, Martinsson A, et al. Impact of chronic obstructive pulmonary disease on morbidity and mortality after myocardial infarction. Open Heart 2014;1(1):e000002.

[11] Enriquez J, de Lemos JA, Parikh SV, et al. Association of chronic lung disease with treatments and outcomes patients with acute myocardial infarction. Am Heart J 2013;165(1):43-9.

[12] Álvarez ÁB, Roubín S R, Cambeiro MCG, et al. In-hospital and follow-up mortality associated to chronic obstructive pulmonary disease in a contemporary cohort of patients with acute coronary syndrome. Eur Heart J 2012;33(Supp 1):1084.

[13] Kjøller E, Køber L, Iversen K, et al. Importance of chronic obstructive pulmonary disease for prognosis and diagnosis of congestive heart failure in patients with acute myocardial infarction. Eur J Heart Fail 2004;6(1):71-7. 
[14] Stefan MS, Bannuru RR, Lessard D, et al. The impact of COPD on management and outcomes of patients hospitalized with acute myocardial infarction. Chest 2012;141(6):1441-8.

[15] Hadi HAR, Zubaid M, Mahmeed WA, et al. Prevalence and prognosis of chronic obstructive pulmonary disease among 8167 middle eastern patients with acute coronary syndrome. Clin Cardiol 2010;33(4):228-35.

[16] Hales CA, Kazemi H. Clinical significance of pulmonary function tests. Pulmonary function after uncomplicated myocardial infarction. Chest 1977;72(3):350-8.

[17] Juvé JI, Sala MF, Puigdevall JMR, et al. Pulmonary volume and cardiopulmonary function in acute myocardial infarction (author's transl). Med Clin (Barc) 1981;77(3):98-103.

[18] Altree T, Bussell L, Nguyen P, et al. Adverse cardiac outcomes after pulmonary function testing with recent myocardial infarction. Respir Med 2019;155:49-50.

[19] Johns DP, Walters JA, Walters EH. Diagnosis and early detection of COPD using spirometry. J Thorac Dis 2014;6(11):1557-69.

[20] Vollmer WM, Gíslason T, Burney P, et al. Comparison of spirometry criteria for the diagnosis of COPD: results from the BOLD study. Eur Respir J 2009;34(3):588-97.
[21] Engström G, Melander 0, Hedblad B. Population-based study of lung function and incidence of heart failure hospitalisations. Thorax 2010;65(7):633-8.

[22] von Krüchten R, Lorbeer R, Schuppert C, et al. Subclinical cardiac impairment relates to traditional pulmonary function test parameters and lung volume as derived from whole-body MRI in a population-based cohort study. Sci Rep 2021;11(1):16173.

[23] Reduced lung capacity linked to cardiovascular disease by inflammation. Science Daily. Available from: https://www.sciencedaily.com/releases/2007/07/0707 02145409.htm

[24] McAllister DA, Maclay JD, Mills NL, et al. Diagnosis of myocardial infarction following hospitalisation for exacerbation of COPD. Eur Respir J 2012;39(5):1097103.

[25] Rothnie KJ, Yan R, Smeeth L, et al. Risk of myocardial infarction (MI) and death following MI in people with chronic obstructive pulmonary disease (COPD): a systematic review and meta-analysis. BMJ Open 2015;5(9):e007824. 